\title{
A OMC Continua Promovendo o Comércio de Forma Desigual: Novas Evidências a Partir dos Anos 1990
}

\author{
Magnus dos Reis ${ }^{*}$, Eduardo Trapp Santarossa ${ }^{\dagger}$, André Filipe Zago de \\ Azevedo ${ }^{\ddagger}$, Sabino da Silva Pôrto Júnior ${ }^{\S}$
}

Sumário: 1. Introdução; 2. A Organização Mundial de Comércio (OMC); 3. Especificação Econométrica e os Dados Utilizados; 4. Resultados Empíricos; 5. Conclusões.

Palavras-chave: Comércio Internacional; Modelo Gravitacional; Dados em Painel.

Códigos JEL: $\quad$ F1, C23, C21.

$\mathrm{O}$ artigo fornece evidências de que a OMC continuou tendo um impacto profundo sobre o comércio de seus países membros, no período 1990-2009, seguindo a contribuição original de Subramanian \& Wei (2007). Para isto, utilizouse o modelo gravitacional, através de efeitos fixos e com o estimador da PMVP, comparando a magnitude da abertura multilateral, entre países desenvolvidos e em desenvolvimento. Os resultados sugerem que os países em desenvolvimento, no período examinado, foram os que mais se beneficiaram do aumento do comércio mundial promovido pela OMC, ao contrário do que havia ocorrido, entre 1950 e 2000, conforme Subramanian \& Wei (2007).

The paper provides evidences that the WTO continues to have a profound impact on its member's trade, in the period 1990-2009, as originally prompted by Subramanian \& Wei (2007). Using a gravity model, based on panel data and the Poisson Pseudo Maximum Likelihood estimator, the paper compares the amount of multilateral trade liberalization in developed and developing countries. The results suggest that developing countries, during the period examined, benefited most from the increase in world trade promoted by WTO, inverting the situation identified by Subramanian \& Wei (2007) in the period 1950-2000.

\footnotetext{
*Doutorando em Economia Aplicada pelo Programa de Pós-Graduação em Economia da Universidade Federal do Rio Grande do Sul-PPGE/UFRGS. E-mail: magnusdosreis@hotmail . com

${ }^{\dagger}$ Mestre em Economia pela UNISINOS. E-mail: etsantar@hotmail.com

${ }^{\ddagger}$ Professor do PPGE da UNISINOS e pesquisador do CNPq. E-mail: aazevedo@unisinos.br

$\S$ Professor do PPGE da UFRGS E-mail: sabino@ppge.ufrgs . br
} 


\section{INTRODUÇÃO}

Muito embora poucos países efetivamente se aproximem de um livre comércio pleno, pode-se dizer que há um "consenso" entre os economistas de que o comércio internacional pode proporcionar uma melhor alocação de recursos e, consequentemente, elevar o bem-estar dos países envolvidos. ${ }^{1}$ Com o intuito de usufruir tais benefícios, vinte e três países estabeleceram, em 1947, o General Agreement on Tariffs and Trade (GATT), cujo objetivo principal era promover o comércio internacional. ${ }^{2}$ Desde então, tem se observado um crescimento das exportações mundiais sempre superior ao do crescimento do PIB mundial.

Apesar do crescimento expressivo do comércio internacional desde a constituição da GATT/OMC, Rose (2004) constatou que esse aumento não poderia ser atribuído à OMC. Os seus resultados sugerem que não haveria evidências suficientes de que a instituição, de fato, teria promovido o comércio internacional. No entanto, este resultado chamou a atenção de muitos economistas e Subramanian \& Wei (2007), mais tarde, forneceram evidências robustas de que a OMC teria tido um forte impacto positivo sobre o comércio internacional, entre 1950 e 2000. A maior contribuição desses autores foi separar o grupo de países da OMC entre aqueles que efetivamente liberalizaram suas economias (países desenvolvidos) e os demais (composto em sua maioria por países em desenvolvimento) que, embora fizessem parte do acordo, não liberalizaram o comércio. Assim, a expansão do comércio teria sido desigual entre os países membros, conforme salientaram os autores, com o aumento do comércio se concentrando nos países desenvolvidos. Esses autores utilizaram o modelo gravitacional log linearizado com dados em painel e efeitos fixos como instrumento de mensuração.

No entanto, Santos Silva \& Tenreyro (2006) fizeram duras críticas a esta abordagem econométrica, entre as quais se destacam o viés da transformação logarítmica, o fracasso da hipótese de homocedasticidade e a forma como os valores nulos são tratados. Segundo eles, esses problemas, normalmente, resultam em estimativas viesadas e ineficientes na presença de heterocedasticidade. Além disso, quando a amostra de países é grande, provavelmente haverá várias observações nas quais o valor do comércio bilateral é zero e isso implicaria em um viés de transformação logarítmica. Visando corrigir essas críticas, Santos Silva \& Tenreyro (2006) sugerem estimar a equação gravitacional através da Pseudo Máxima Verossimilhança de Poisson (PMVP).

A partir dessas críticas, este artigo tem como objetivo mensurar se a OMC promoveu o comércio internacional, mantendo a separação de países proposta por Subramanian \& Wei (2007), abrangendo um período mais recente, entre 1990 e 2009, quando houve uma liberalização mais intensa dos países em desenvolvimento. Além disso, seguindo a recomendação de Santos Silva \& Tenreyro (2006), comparase a magnitude da abertura multilateral, utilizando-se o modelo gravitacional com efeitos fixos e com o estimador da PMVP. Contudo, deve-se ter cuidado ao comparar diretamente os resultados obtidos neste artigo com aqueles encontrados por Subramanian \& Wei (2007). De fato, esse não é o objetivo desse artigo, pois os trabalhos utilizaram estimadores distintos e diferentes períodos e países na amostra. Ainda, é provável que as estimativas encontradas por Subramanian \& Wei (2007) sejam viesadas e ineficientes, uma vez que utilizaram o estimador de Efeitos Fixos e não a PMVP.

0 artigo está dividido em quatro seções, além desta introdução. A seção 2 apresenta os princípios básicos, as rodadas de negociação e as principais assimetrias do sistema multilateral de comércio, conduzido pela OMC, bem como a evolução recente do regionalismo. A seção 3 faz uma breve revisão dos modelos gravitacionais, especifica a equação a ser estimada e descreve os dados utilizados. A seção 4 apresenta os resultados encontrados e, por fim, a seção 5 oferece as conclusões.

\footnotetext{
${ }^{1}$ Dos argumentos contrários ao livre comércio, os dois mais refinados e aceitos são: melhoria nos termos de troca, válida apenas para a imposição de tarifas de importação em países grandes e subsídios a setores intensivos em tecnologia, dadas as externalidades positivas que este setor pode gerar.

${ }^{2}$ Em 1995 o acordo foi incorporado à Organização Mundial de Comércio (OMC).
} 


\section{A ORGANIZAÇÃO MUNDIAL DE COMÉRCIO (OMC)}

A OMC é a instituição responsável por promover as rodadas de negociações multilaterais (multilateralismo) e regulamentar os Acordos Preferenciais de Comércio (Regionalismo). Além de regular os princípios básicos de todo sistema, ela também é a instituição responsável por solucionar eventuais controvérsias. ${ }^{3}$ A seguir, são apresentadas algumas características da abertura multilateral e regional.

\subsection{O Multilateralismo}

As características deste sistema envolvem um comércio sem discriminação, o mais previsível possível, mais competitivo e com mais beneficios aos países menos desenvolvidos. A seguir são apresentados os princípios da instituição, um pequeno histórico das rodadas de negociações multilaterais e as assimetrias do sistema.

\subsubsection{Princípios do sistema de comércio}

O principal princípio do sistema de comércio multilateral conduzido pela OMC é a Cláusula da Nação Mais Favorecida (MFN). Ela estabelece que os seus países membros devem conceder tratamento igual a todos os demais países da instituição, isto é, os países não poderão favorecer apenas um único país, através de uma redução tarifária, por exemplo, sem que isso seja estendido a todos demais membros da OMC. Outro princípio importante se refere a questão do Tratamento Nacional, que exige que produtos e serviços estrangeiros sejam tratados da mesma forma que são tratados os produtos e serviços domésticos, após as mercadorias estrangeiras entrarem no mercado doméstico. 0 mesmo se aplica para marcas estrangeiras, direitos autorais e patentes. ${ }^{4}$

Outro aspecto é a luta por um comércio gradualmente mais livre através das negociações comerciais. Muito embora a redução das barreiras comerciais seja um dos meios mais óbvios de incentivar o comércio, ${ }^{5}$ outras questões começaram a serem debatidas, tais como aspectos burocráticos, barreiras não tarifárias e políticas cambiais. No entanto, muitas vezes a abertura comercial vai requerer ajustes internos e, devido a isso, os acordos da OMC permitem que os países introduzam essas mudanças de maneira gradual, através de "liberalização progressiva". Além disso, países em desenvolvimento recebem mais tempo para cumprir as suas obrigações (OMC, 2013).

No que diz respeito à previsibilidade, os países devem ser o mais transparente possível e suas políticas comerciais devem ser críveis para reduzir as incertezas. A promessa de não aumentar uma barreira comercial pode ser tão importante como a redução de uma, porque ela dá às empresas uma visão mais clara de suas oportunidades futuras. Com estabilidade e previsibilidade, o investimento é estimulado, empregos são criados e os consumidores podem desfrutar plenamente dos benefícios de uma maior concorrência, escolha e preços mais baixos. Portanto o sistema multilateral de comércio é uma tentativa, por parte dos governos, de tornar o ambiente de negócios estável e previsível (OMC, 2013).

Outro aspecto interessante é impulsionar uma concorrência leal. Muitas vezes a OMC é definida como uma instituição de "livre comércio", no entanto isto não é inteiramente verdadeiro, pois em circunstâncias limitadas o sistema permite a imposição de tarifas de importação e outras formas de proteção. Na

\footnotetext{
${ }^{3} \mathrm{O}$ mecanismo de resolução de disputas comerciais envolve cinco etapas, desde consultas iniciais entre os países diretamente envolvidos até a implementação de um painel de especialistas. A duração varia de 1 ano (sem apelação) a 15 meses (com apelação) e ela dá o direito de retaliação (OMC-World Trade Organization, 2013).

${ }^{4}$ Dado que o tratamento nacional aplica-se apenas após os produtos ingressarem no mercado doméstico, a cobrança de tarifa de importação não é considerada uma violação do tratamento nacional, mesmo se os produtos produzidos localmente não sejam taxados com um imposto equivalente. Um exemplo de violação desta cláusula seria cobrar um imposto nacional (que abrange todos os produtos do mercado independentemente de qual for sua procedência) mais alto de produtos importados do que os nacionais (OMC, 2013).

${ }^{5}$ Entendem-se como barreiras os direitos aduaneiros (ou tarifas), medidas como a proibição de importação e cotas que restringem quantidades importadas.
} 
realidade, o sistema pode ser mais bem definido como um sistema de regras dedicadas à concorrência aberta, justa e leal. As regras da MFN e do Tratamento Nacional são projetadas para garantir condições "justas" de comércio. Porém, muitos países praticam o dumping e concedem subsídios, práticas essas que são consideradas desleais pela OMC. Para esses casos, a instituição permite que os governos possam se defender através da cobrança de direitos de importação adicionais para compensar os danos causados por comércio desleal (OMC, 2013). Por fim, a instituição incentiva o desenvolvimento e a reforma econômica, pois países em desenvolvimento necessitam de maior flexibilidade temporal para implementarem acordos e este benefício é concedido apenas aos mesmos (OMC, 2013).

Apesar das limitações ao livre comércio permitidas pela própria OMC, o período de maior crescimento do volume de comércio internacional no século XX ocorreu justamente após a criação do GATT, como mostra a Tabela 1 . No período 1950-1973, o crescimento médio anual do volume de comércio atingiu a $8,2 \%$, muito acima do período entre guerras (1913-1950) e superior também ao início do século, quando se vivia o auge da chamada $1^{\text {a }}$ onda de globalização. Mesmo após o término do acordo de Bretton-Woods, em 1973, o comércio manteve taxas de crescimento significativas, superiores ao da primeira metade do século XX. Embora o aumento do comércio internacional não possa ser atribuído exclusivamente à formação da OMC, uma parcela importante teve a contribuição deste organismo. De acordo com Subramanian \& Wei (2007), a OMC seria responsável por um comércio internacional adicional da ordem de $120 \%$ (ou US\$ 8 trilhões), apenas no ano de 2000.

\subsubsection{As rodadas de negociações multilaterais}

Desde 1947, já foram realizadas 8 rodadas de negociações multilaterais e, atualmente, a rodada de Doha está em curso. Conforme pode ser observado na Tabela 2, a duração, o número de países membros e a complexidade dos temas foram aumentando a cada rodada. Nas rodadas iniciais, o foco era a negociação do comércio de produtos industrializados. Especificamente nas seis primeiras rodadas, o tema predominante foi a busca de reduções tarifárias. A partir da sétima rodada, diversos novos temas foram incluídos nas negociações, incluindo medidas antidumping, subsídios, salvaguardas e compras governamentais. Devido ao maior número de países-membros, que já chegava a 99 na época de sua realização, e a maior complexidade dos temas, a rodada Tóquio se estendeu por seis anos, a mais longa até então.

Na rodada Uruguai outras temas foram acrescentados na pauta de negociação, tais como a preservação das patentes sobre propriedade intelectual (TRIPS) e a liberalização do setor de serviços. Esses novos temas têm grande importância nos mercados dos países em desenvolvimento, que até então estavam praticamente excluídos do processo de negociação. Também houve significativos avanços nas negociações sobre as regras da OMC em matéria de subsídios, barreiras técnicas, salvaguardas, regras de origem, licenças de importação, antidumping, medidas fitossanitárias, e investimentos relacionados ao comércio (TRIMS), entre outros. Além disso, para tornar o comércio mais previsível, onde os agentes econômicos tivessem confiança de que as barreiras não seriam elevadas arbitrariamente, houve um aumento expressivo na imposição de tetos para tarifas e barreiras não-tarifárias para os países em desenvolvimento. No caso de produtos industrializados, o percentual de produtos com tetos tarifários passou de $21 \%$ para 73\% nesse grupo de países (GATT, 1994).

No que se refere ao valor das tarifas, houve a redução das tarifas de importação de bens industriais em países desenvolvidos de $40 \%$ (de uma média de 6,3\% para 3,8\%). No caso dos países em desenvolvimento,

Tabela 1. Crescimento do Volume de Comércio e PIB Mundial (1900-2010). *

\begin{tabular}{lccccc}
\hline Variação média anual & $1900-1913$ & $1913-1950$ & $1950-1973$ & $1973-2000$ & $2000-2010$ \\
\hline PIB & 2,5 & 2,0 & 5,1 & 2,9 & 3,0 \\
Comércio de Bens & 4,3 & 0,6 & 8,2 & 4,9 & 5,0 \\
\hline
\end{tabular}

* Variação percentual média ao ano. Fonte: OMC. 
Tabela 2. Rodadas de negociações multilaterais realizadas.

\begin{tabular}{lcccl}
\hline Ano & Local & Nome & $\mathbf{N}^{\circ}$ de países & Temas \\
\hline 1947 & Genebra & 23 & tarifas \\
1949 & Annecy & & 13 & tarifas \\
1951 & Torquay & & 38 & tarifas \\
1956 & Genebra & & 26 & tarifas \\
$1960-1961$ & Genebra & Rodada Dillon & 26 & tarifas \\
$1964-1967$ & Genebra & Rodada Kennedy & 62 & tarifas e medidas antidumping \\
$1973-1979$ & Genebra & Rodada Tóquio & 102 & tarifas, barreiras não tarifárias e \\
& & & & estrutura institucional \\
$1986-1994$ & Genebra & Rodada Uruguai & 123 & tarifas, barreiras não tarifárias, \\
& & & & serviços, propriedade intelectual, \\
& & & & solução de controvérsias, têxteis, \\
& & & 155 & agricultura, criação da OMC \\
& & & & nesmos temas acima, com ênfase \\
$2001-?$ & Doha & Rodada Doha & &
\end{tabular}

Fonte: Elaboração própria com base no OMC (2013).

a redução foi variável, mas bastante significativa para a maioria dos países. No caso de Índia, Coreia do Sul e Cingapura, a tarifa média de importação declinou em mais de $50 \%$ para produtos industrializados. Na Índia, a queda foi maior, passando de uma tarifa média de $71,4 \%$ antes da rodada Uruguai para $32,4 \%$ após a rodada (GATT, 1994). ${ }^{6}$ De acordo com Thorstensen (2001), todas as oito rodadas da OMC já concluídas podem ser consideradas um sucesso, quando se tem em mente que as médias tarifárias aplicadas aos produtos eram de 40\% em 1947 e caíram para 5\% em 1994, quando se finalizou a Rodada Uruguai.

A rodada de Doha, lançada em 2001, tinha objetivos ambiciosos, pois abrangia não apenas o liberalizar o comércio de manufaturas, produtos agrícolas e serviços, mas também uma série de temas relacionados indiretamente com o comércio (tais como propriedade intelectual, defesa da concorrência estrangeira, regras de investimento, entre outros). A meta inicial era concluir as negociações para a grande parte desses temas até $1^{\circ}$ de Janeiro de 2005. No entanto, essa rodada permanece aberta há mais de 11 anos e as negociações seguem sem avançar, o que pôs em cheque o futuro do sistema.

Isso reflete dois problemas estruturais na forma como são feitas as negociações na OMC. O primeiro se deve a dois fatos: que as decisões na OMC devem ser consensuais e ao aumento do número de países membros. Uma vez que as negociações comerciais iniciaram, em 1947, com apenas 23 países e que, quando Doha foi lançada eram 155, a abertura multilateral não está conseguindo avançar devido à dificuldade de consenso sobre os temas. Já o segundo é decorrente do audacioso objetivo inicial, uma vez que a ideia era conseguir um grande acordo no qual englobaria manufaturas, serviços e produtos agrícolas. No entanto, não foi possível chegar a um acordo para o setor agrícola, pois os países desenvolvidos não abriram mão de suas políticas protecionistas nesse setor. Esta situação vem frustrando muitos países, fazendo com que o multilateralismo fosse preterido ao regionalismo no mundo inteiro (The Economist, 2012).

\footnotetext{
${ }^{6}$ Outros aspectos importantes negociados na rodada Uruguai foram o estabelecimento de regras mais precisas para medidas antidumping e direitos compensatórios e a eliminação das "Restrições Voluntárias às Exportações” até 1999.
} 


\subsubsection{Assimetrias da OMC, contradições e evidências empíricas}

A primeira das assimetrias existentes na OMC, segundo Subramanian \& Wei (2007), é a diferença de tratamento que a OMC fez entre países desenvolvidos e em desenvolvimento. Os membros desenvolvidos tiveram um cronograma mais rigoroso de obrigações do que os países em desenvolvimento, em termos de liberalização comercial (barreiras tarifárias e não tarifárias). A segunda assimetria está relacionada à discriminação feita por países membros a não membros da OMC, uma vez que as obrigações de reciprocidade e o status de MFN eram estendidos apenas a membros da instituição. A terceira se deve a diferença na forma que ocorreu a liberalização comercial entre os setores. Como os países desenvolvidos foram os precursores da instituição, foram eles que participaram mais ativamente das rodadas de negociações iniciais e, assim, era natural que fossem negociados primeiramente os setores nos quais eles tinham interesse em exportar, enquanto os setores nos quais os países em desenvolvimento tinham interesse ficaram à margem das negociações. Por fim, a quarta assimetria reflete a diferença de tratamento que os novos países membros recebem em comparação aos que ingressaram antigamente. Os novos membros recebem um cronograma de liberalização mais rigoroso se comparado aos países que são membros antigos da OMC.

Levando em conta essas assimetrias e utilizando o modelo gravitacional, Subramanian \& Wei (2007) contrariam os resultados Rose (2004) ao fornecerem evidências robustas de que a OMC tem tido um forte impacto positivo no comércio, gerando um impacto adicional de cerca de $120 \%$ no comércio mundial. No entanto, o impacto entre os países teria sido desigual. Primeiro, os países industriais, que participaram mais ativamente do que os países em desenvolvimento nas negociações comerciais recíprocas, beneficiaram-se de um grande aumento do comércio. Em segundo lugar, o comércio bilateral foi maior quando ambos os parceiros se comprometeram com a liberalização, quando comparado a uma situação em que apenas um parceiro efetivamente liberalizou sua economia. Terceiro, os setores que não se beneficiaram do processo de liberalização não usufruíram de aumento no comércio bilateral.

Essas assimetrias, de fato, criaram durante muito tempo um viés de comércio entre os membros da OMC, que realmente reduziram o grau de protecionismo para os demais integrantes do acordo, abrangendo principalmente os países desenvolvidos. No entanto, em um período mais recente, especialmente a partir da rodada Uruguai, os países em desenvolvimento passaram a efetivamente liberalizar o comércio, seguindo as orientações da OMC. O exemplo mais claro disso foi a imposição de tetos tarifários, que reduziram significativamente as tarifas de importação até então vigentes para os demais membros da OMC. Ao mesmo tempo, a liberalização dos países desenvolvidos foi mais tímida, principalmente porque já eram economias muito mais abertas ao comércio, por terem reduzido seu aparato protecionista no período pré-rodada Uruguai (1947-1986). Ou seja, a partir da metade dos anos 1990, a liberalização mais intensa ocorreu nos países em desenvolvimento que eram membros da OMC.

0 resultado dessa maior liberalização pode ser observado pelo aumento nos fluxos de comércio dos países em desenvolvimento pertencentes à OMC. Conforme mostra a Tabela 3, no período 1990-2009, as importações desse grupo de países cresceram, em média, 10,5\% ao ano. Já os países desenvolvidos tiveram um crescimento menor de suas importações, no mesmo período, chegando a 5,8\% ao ano. Portanto, a principal assimetria de comércio entre os membros da OMC, originalmente destacada por Subrama-

Tabela 3. Evolução das Importações dos Países da OMC por grau de Desenvolvimento. *

\begin{tabular}{lccc}
\hline Todos países da OMC & $\begin{array}{c}1990 \\
\text { (US\$ milhões) }\end{array}$ & $\begin{array}{c}2009 \\
\text { (US\$ milhões) }\end{array}$ & $\begin{array}{c}\text { Média de Crescimento } \\
1990-2009\end{array}$ \\
\hline Países desenvolvidos importadores & $2.584 .353,92$ & $7.561 .283,93$ & $5,81 \%$ \\
Países em desenvolvimento importadores & $637.605,76$ & $4.278 .625,09$ & $10,54 \%$ \\
\hline
\end{tabular}

* Classificação de acordo com a UNCTAD. Fonte: OMC. 
nian \& Wei (2007), parece ter se invertido a partir dos anos 1990. No período mais recente, especialmente com as medidas adotadas a partir da Rodada Uruguai, foram os países em desenvolvimento que mais liberalizaram suas economias de forma multilateral e, como consequência disso, foram eles que experimentaram o maior incremento comercial.

Por fim, outro aspecto constantemente debatido e criticado no sistema de comércio é que existem algumas brechas que tornam possível violar os princípios básicos da OMC. A violação mais comum é a formação de APCs que podem liberalizar o comércio apenas dentro do bloco, muitas vezes discriminando as mercadorias extrabloco. ${ }^{7}$ Assim, os blocos econômicos contrariam a cláusula MFN. É possível também que países desenvolvidos concedam a países em desenvolvimento um acesso preferencial aos seus mercados sem estender este mesmo benefício a países desenvolvidos. Esta brecha é conhecida como Sistema Geral de Preferência (GSP) e também viola a cláusula da MFN. Por fim, um país também pode elevar suas barreiras tarifárias contra produtos de países que são negociadas de "forma injusta" dentro do país lesado, este é o caso do dumping. ${ }^{8}$

\subsection{Regionalismo}

O regionalismo não é um fenômeno recente. Segundo Bhagwati, Krishna \& Panagariya (1999), a primeira onda do regionalismo ocorreu no século XX, mais especificamente no final da década de 1950 e durante a década de 1960. Essa primeira onda envolvia apenas setores industriais específicos, removia unicamente as barreiras de importação, era composta somente por países com o mesmo nível de desenvolvimento e foi dirigida pelos governos, pois era baseada na política de substituição de importações. Já a segunda onda envolve quase todos os setores, inclui países com diferentes níveis de desenvolvimento, disciplinas comuns, regimes regulatórios e tem sido liderada pelas empresas ao buscarem novos mercados para suas exportações. Nesse sentido, a segunda onda do regionalismo, que ocorre a partir de 1990, tem uma integração mais profunda em comparação à primeira. Além disso, houve um aumento expressivo na criação de acordos bilaterais e de blocos econômicos no mundo inteiro. A Figura 1 demonstra justamente este crescimento no número de APCs registrados na OMC. Para se ter uma ideia, o número total de APCs em vigor notificados à OMC em 1999 era maior que o número de países membros desta instituição.

Após a apresentação das características do sistema de comércio, a próxima a seção apresenta o modelo gravitacional, que foi o instrumento utilizado para descobrir se a OMC conseguiu promover o comércio mundial e para comprar a abertura multilateral à regional. A escolha pela equação gravitacional se deve ao fato de que ela tem sido o principal instrumento utilizado pelos pesquisadores para mensurar o impacto dos APCs, uma vez que ela é capaz de explicar o volume de comércio bilateral de forma muito satisfatória mesmo se os APCs não tivessem sido formados.

\section{ESPECIFICAÇÃO ECONOMÉTRICA E OS DADOS UTILIZADOS}

O modelo gravitacional tem origem na lei da gravitação universal de Isaac Newton, formulada na metade do século XVII, na qual postula que a força de atração entre dois corpos é diretamente proporcional ao produto de suas massas e inversamente proporcional ao quadrado de sua distância. No século XIX, a lei gravitacional foi absorvida por diversas áreas do conhecimento humano, tais como as ciências sociais e exatas. Mais especificamente na ciência econômica, Tinbergen (1962), Poyhonen (1963) e Linnemann (1966) adaptaram a lei da gravidade à economia para estimar o fluxo de comércio bilateral entre dois

\footnotetext{
${ }^{7} \mathrm{O}$ artigo XXIV é o que regula os Acordos Preferenciais entre países desenvolvidos e a Enabling Clause, a que estipula as regras para Acordos Preferenciais entre países em desenvolvimento.

${ }^{8}$ Muito embora a OMC só permita essas exceções ao livre comércio sob condições estritas, em geral, a cláusula da MFN garante que quando um país reduz uma barreira comercial, ou ainda, quando abre seu mercado, isso deverá ser feito para todos os seus parceiros comerciais, sejam eles países ricos ou pobres.
} 
Figura 1. Número de notificações de APCs à OMC.

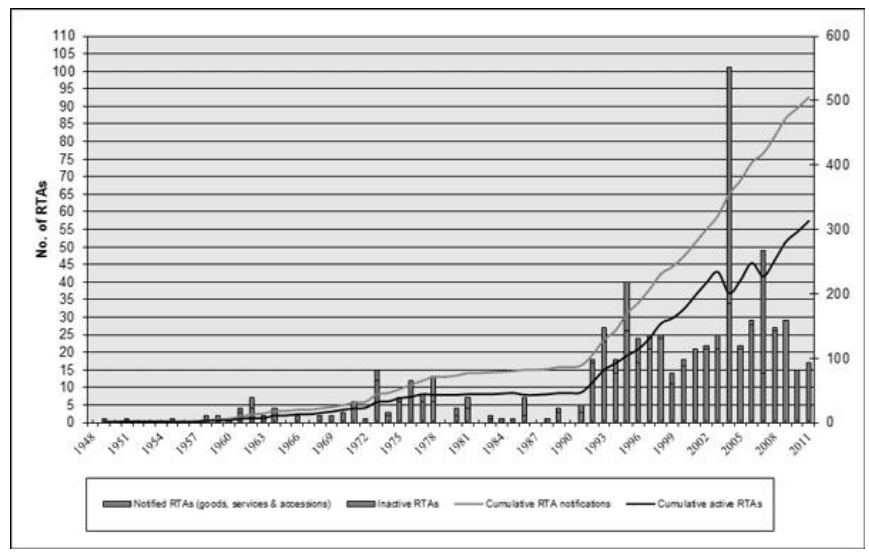

Fonte: OMC (2013).

países. Foram esses autores que propuseram o modelo gravitacional ao fornecer as variáveis básicas que são utilizadas, em alguns casos, até hoje para determinar o comércio bilateral entre os países.

A equação gravitacional tradicional parte da ideia básica de que o comércio entre dois países é diretamente proporcional ao Produto Interno Bruto (PIB) de suas economias e inversamente proporcional à distância entre eles. Sua forma mais simples pode ser descrita da seguinte maneira:

$$
\ln m_{j i}=\beta_{0}+\beta_{1} \ln Y_{j}+\beta_{2} \ln \left(\frac{Y_{j}}{N_{j}}\right)+\beta_{3} \ln Y_{i}+\beta_{4} \ln \left(\frac{Y_{i}}{N_{i}}\right)+\beta_{5} \ln \operatorname{dist}_{j i}+\epsilon_{j i},
$$

onde $m_{j i}$ representa as importações bilaterais entre os países $j$ e $i$; $Y_{i}$ é o PIB do país $i$ e $Y_{j}$ é o PIB do país $j$; $Y_{i}$ é a população do país $i$ e $Y_{j}$ é a população país $j$; dist $_{j i}$ é a distância entre os países $j$ e $i$; e $\epsilon_{j i}$ é o erro.

Entretanto, apesar de conseguir explicar, de forma satisfatória, o comércio bilateral entre os países, o modelo gravitacional carecia de fundamentação teórica. Assim, Anderson (1979), Deardorff (1998), e Anderson \& van Wincoop (2003) derivaram o modelo gravitacional do modelo de Heckscher-Ohlin, assim como Bergstrand (1985), Helpman (1987) e Helpman \& Krugman (1995) também, porém através dos modelos de concorrência imperfeita, dando a base teórica que faltava ao modelo. Mais recentemente, Baldwin \& Taglioni (2006) também fundamentaram a equação gravitacional.

Além disso, com o passar dos anos, os pesquisadores perceberam que outros fatores poderiam afetar o volume de comércio bilateral e, assim, passaram a incluir na equação gravitacional outras variáveis, a fim de aumentar o poder de explicação do modelo. Nesse sentido, dummies foram inseridas para representar algumas características que se presumia que também afetassem o volume de comércio entre os países. Por exemplo, espera-se que países com um idioma oficial em comum e que partilhem uma fronteira tenham maiores facilidades de negociar e, sendo assim, apresentem um volume de comércio maior em comparação aos países que não apresentem tais características. Além disso, Aitken (1973) foi um dos pioneiros a avaliar o impacto da criação dos APCs sobre os fluxos de comércio. Nesse caso, o modelo gravitacional refletia o comércio "normal" entre dois países sem a presença de um APC, enquanto a variável dummy relacionada ao APC captava o comércio que podia ser atribuído exclusivamente à criação do mesmo.

Nesse primeiro momento, a maior parte dos trabalhos realizados estimou o modelo gravitacional através de Mínimos Quadrados Ordinários (MQO) e com dados em cross-section ou dados agrupados (pooled data). Esta arquitetura pode ser considerada a abordagem tradicional do modelo. Entretanto, as estimativas tradicionais dos modelos gravitacionais passaram a ser alvo novamente de críticas. Wei (1996), 
Deardorff (1998), e Anderson \& van Wincoop (2003) afirmaram que o modelo gravitacional usual pode apresentar problemas de especificação ao ignorar a "resistência multilateral" e "isolamento" dos países. Além disso, segundo Egger (2005), o modelo gravitacional com dados agrupados e em cross-section sofre problemas de especificação, uma vez que ele não é capaz de lidar com a heterogeneidade bilateral do exportador e importador, que é extremamente provável que esteja presente nos fluxos de comércio bilaterais. Ademais, a teoria econômica internacional avançou e novos conceitos sobre o regionalismo foram desenvolvidos. Um deles foi proposto por Wonnacott \& Lutz (1989), Summers (1991) e Krugman (1991), ao criarem o conceito de "parceiro natural de comércio" para países próximos geograficamente e que possuam elevados níveis de comércio bilateral. Esse novo conceito teve um impacto direto sobre a forma que vinha sendo estimada a equação gravitacional, fazendo com que uma nova forma de estimação fosse proposta. Assim, visando corrigir todos esses problemas de má especificação, Matyas (1997), Anderson \& van Wincoop (2003) e Baldwin \& Taglioni (2006) sugerem a estimação da equação gravitacional em dados em painel e efeitos fixos.

Apesar de certo consenso da necessidade de estimar o modelo com dados em painel e efeitos fixos, a maneira de especificar o efeito fixo e qual estimador utilizar ainda vem provocando um grande debate. ${ }^{9}$ Santos Silva \& Tenreyro (2006) e Magee (2008) defenderam a utilização do estimador PMVP, enquanto Cheng \& Wall (2004) e Baldwin \& Taglioni (2006) trabalharam com o estimador LSDV. Por outro lado, o estimador HT foi utilizado por Egger (2005) e Carrere (2006). Contudo, Santos Silva \& Tenreyro (2006) fizeram duras críticas à prática usual de estimar o modelo gravitacional com transformação logarítmica. Segundo eles, essa prática incorre em um viés da transformação logarítmica, dada a forma como os valores nulos são tratados, e fracassa na hipótese de homocedasticidade. Os autores afirmam ainda que esses problemas, normalmente, resultam em estimativas viesadas e ineficientes na presença de heterocedasticidade. ${ }^{10}$

Santos Silva \& Tenreyro (2006) utilizaram simulações de Monte Carlo para comparar vários estimadores para o modelo gravitacional, entre eles: MQO linear e não linear, tobit e a Pseudo Máxima Verossimilhança de Poisson (PMVP). ${ }^{11}$ Os autores demonstraram que a melhor forma de estimar o modelo gravitacional seria através da PMVP, pois as estimativas dos parâmetros são consistentes mesmo com erros heterocedásticos e ainda é possível incluir na análise os fluxos de comércio bilaterais com valores iguais a zero sem fazer qualquer transformação. Magee (2008); Recalde, Florensa \& Iturralde (2008); Siliverstovs \& Schumacher (2007); Westerlund \& Wilhelmsson (2009) corroboram com a visão de Santos Silva \& Tenreyro (2006), ao afirmarem que os resultados encontrados pela equação gravitacional são muito sensíveis ao método utilizado e que o PMVP seria o mais confiável.

Outra alternativa para lidar com o problema de zeros na amostra é a proposta por Helpman, Melitz \& Rubinstein (2008). No artigo, os autores derivam um modelo gravitacional a partir de um modelo de firmas heterogêneas e advertem para o possível viés nas estimativas dos parâmetros tanto pela existência de zeros (viés de seleção) quanto pela existência de heterogeneidade das firmas. Resumidamente, a sugestão para correção dos problemas é estimar o modelo gravitacional em dois estágios: primeiramente, através de um modelo probit, com o objetivo de identificar a probabilidade de o comércio ser igual a

\footnotetext{
${ }^{9}$ Para maiores informações sobre formas alternativas de especificar o efeito fixo veja Reis (2012).

${ }^{10}$ Segundo Santos Silva \& Tenreyro (2006), a desigualdade de Jensen afirma que $\mathrm{E}[\ln y] \neq \ln \mathrm{E}[y]$, ou seja, que o valor esperado do logaritmo de uma variável aleatória é diferente do logaritmo do valor esperado, e isso implica que a prática padrão de interpretar os parâmetros dos modelos log linearizados estimados por MQO em termos de elasticidades pode ser altamente enganadora na presença de heterocedasticidade, uma vez que o valor esperado do logaritmo de uma variável aleatória depende dos momentos de ordem superior de sua distribuição. Portanto, se os erros são heteroscedásticos, os erros transformados serão geralmente correlacionado com as covariáveis.

${ }^{11}$ Segundo Wooldridge (2010, p.558), a hipótese de normalidade como distribuição padrão da regressão linear nem sempre é a melhor alternativa, pois a distribuição normal é de variáveis contínuas que podem assumir quaisquer valores e isso não ocorre para dados de contagem. Nos dados de contagem, a variável dependente pode assumir poucos valores e sua distribuição pode ser muito diferente da distribuição normal. Nesse sentido, para dados de contagem a distribuição mais indicada seria a de Poisson. Quando se refere à Pseudo Máxima Verossimilhança de Poisson, se assume que a distribuição de Poisson não seja inteiramente correta nos dados utilizados.
} 
zero e, em seguida, adiciona à equação final essa probabilidade. Contudo, o estimador escolhido para estimador o modelo gravitacional foi a PMVP.

Diferentemente do artigo de Subramanian \& Wei (2007), que estimaram a equação log linearizada com dados de cinco em cinco anos para o período de 1950 a 2000, o presente artigo estimará a equação gravitacional através da PMVP e dois efeitos fixos $\left(\alpha_{j i}\right.$ e $\left.\alpha_{t}\right)$, aliviando qualquer risco de incorrer em viés da transformação logarítmica e produzindo resultados consistentes mesmo na presença de erros heterocedásticos. $O$ efeito fixo $\alpha_{j i}$ captará todas as características não observadas, que são constantes ao longo do tempo para cada par de países, mas que influenciam os fluxos de comércio. Nesse sentido, levase em conta a possibilidade de existência de parceiros naturais de comércio, a resistência multilateral, o isolamento dos países, aspectos culturais e institucionais, aliviando as críticas anteriores. Todas essas características não observadas, em alguns casos, não são mensuráveis, porém elas afetam os fluxos de comércio e devem ser levadas em conta pelo modelo. Justamente dessa maneira que um possível problema com heterogeneidade é controlado no modelo. Não obstante, a inclusão do efeito fixo $\alpha_{j i}$ leva em conta inclusive as variáveis observáveis que usualmente são utilizadas na equação gravitacional, entre as quais a distância entre os países, a extensão da área territorial do importador e do exportador, bem como as dummies de fronteira, litoral e idioma em comum. ${ }^{12}$ Por outro lado, o efeito fixo específico de cada ano $t, \alpha_{t}$, captura choques não percebidos pelas variáveis incluídas no modelo, tais como o ciclo de negócios, fatores climáticos, guerras, entre outros, que podem determinar mudanças nos fluxos de comércio.

Além dos dois efeitos fixos, a equação a ser estimada terá como variável dependente as importações dos países e como independentes o PIB e a população do importador e exportador. Além disso, foram inseridas várias variáveis dummies para capturar o efeito da abertura regional e multilateral. As dummies incluídas no modelo foram construídas, conforme descrito na Tabela 4. Seguindo Soloaga \& Winters (2001), foram incluídas três variáveis dummies para cada bloco, sendo uma delas para capturar o efeito da criação do APC sobre o comércio intrabloco, outra para as importações totais do bloco e a última para as exportações totais do bloco. Através da inserção dessas variáveis, esses autores conseguiram analisar não somente o impacto sobre o fluxo de comércio bilateral que pode ser exclusivamente atribuído à formação do bloco, mas também se houve criação ou desvio de comércio com a formação do mesmo, bem como se ocorreu o que ambos os autores denominam de "desvio de exportação". Por outro lado, as dummies que representam a abertura multilateral promovida pela OMC foram embasadas pelo artigo de Subramanian \& Wei (2007).

Assim, parte-se agora para definir o modelo a ser estimado neste artigo, representado pela equação (2). A matriz $\boldsymbol{X}_{j i t}$ inclui o PIB e a população dos importadores e exportadores, além das dummies da abertura regional e multilateral. Portanto, os coeficientes de interesse serão estimados pelo vetor coluna $\beta_{k}$.

$$
m_{j i t}=\alpha_{t}+\alpha_{j i}+\sum_{k=1}^{n} \beta_{k} \cdot \boldsymbol{X}_{j i t}+\epsilon_{j i t},
$$

onde $m_{j i t}$ é vetor coluna das importações dos países importadores $j$ e exportadores $i$ no ano $t ; \boldsymbol{X}_{j i t}$ é a matriz com as $k$ variáveis dos importadores $j$ e exportadores $i$ no ano $t ; \beta_{k}$ é o vetor de parâmetros das variáveis $\boldsymbol{X}_{j i t} ; \alpha_{j i}$ é o efeito fixo das características não observadas que são constantes no tempo para os pares de países $j i$; $\alpha_{t}$ é o efeito fixo específico de cada ano $t$ que é comum para todos pares de países $j i$; e $\epsilon_{j i t}$ é o vetor de resíduos randômicos do ano $t$.

Finalmente, no que diz respeitos aos dados, a amostra utilizada engloba 52 países para um período de 20 anos, de 1990 a 2009. ${ }^{13}$ Estas nações representavam, em termos de comércio mundial, aproximadamente, $78 \%$ das importações mundiais totais para o período analisado. 0 trabalho apresenta 2.652

${ }^{12}$ Mesmo essas variáveis não sendo colineares com o efeito fixo $\alpha_{j i}$, não será possível mensurá-las, nem quaisquer outras, que sejam constantes no tempo, quando o efeito fixo for assim especificado.

${ }^{13}$ A lista dos países incluídos na análise é a seguinte: Argentina, Brasil, Paraguai, Uruguai, Canadá, México, Estados Unidos, Peru, Equador, Bolívia, Colômbia, Venezuela, Cingapura, Filipinas, Indonésia, Malásia, Tailândia, Austrália, Nova Zelândia, Costa Rica, 
Tabela 4. Dummies inseridas no modelo.

\begin{tabular}{ll}
\hline Sigla & Forma de construção \\
\hline APC & $\begin{array}{l}\text { Dummy que assume valor } 1 \text { se o importador } i \text { e o exportador } j \text { forem membros de } \\
\text { um APC e, } 0 \text { caso contrário. }\end{array}$ \\
APC_OMC & $\begin{array}{l}\text { Dummy que assume valor } 1 \text { se o importador } i \text { é membro de um APC, porém o } \\
\text { exportador } j \text { é membro da OMC e não faz parte do acordo e 0, caso contrário. }\end{array}$ \\
APC_NOMC & $\begin{array}{l}\text { Dummy que assume valor } 1 \text { se o importador } i \text { é membro de um APC, porém o } \\
\text { exportador } j \text { não faz parte do acordo e não é membro da OMC e 0, caso contrário. }\end{array}$ \\
OMCD_OMCD & $\begin{array}{l}\text { Dummy que assume valor } 1 \text { se ambos } i \text { e } j \text { (importador e exportador) são países } \\
\text { desenvolvidos membros da OMC e não possuem um APC, e 0, caso contrário. }\end{array}$ \\
OMCD_OMCS & $\begin{array}{l}\text { Dummy que assume valor } 1 \text { quando o país importador, desenvolvido, } i \text { e o país } \\
\text { exportador, subdesenvolvido, } j \text {, ambos forem membros da OMC e sem a presença de } \\
\text { um APC e 0, caso contrário. }\end{array}$ \\
OMCD_NOMC & $\begin{array}{l}\text { Dummy que assume valor } 1 \text { quando o país importador } i \text { for desenvolvido e membro } \\
\text { da OMC e o exportador } j \text { não seja membro da OMC e nem tenham um APC em } \\
\text { comum e 0, caso contrário. }\end{array}$ \\
OMCS_OMCS & $\begin{array}{l}\text { Dummy que assume valor } 1 \text { para quando o importador } i \text { e o exportador } j \text { forem } \\
\text { países subdesenvolvidos, membros da OMC e que não façam parte de um APC, e 0, } \\
\text { caso contrário. } \\
\text { Dummy que assume valor 1 para o país subdesenvolvido importador } i \text { for membro } \\
\text { da OMC e país exportador } j \text { não seja menbro OMC e ambos não tenham um APC em } \\
\text { comum e 0, caso contrário. } \\
\text { Dummy que assume valor 1 quando o importador } i \text { e o exportador } j \text { não sejam } \\
\text { membros da OMC e não façam parte de um APC e, 0 caso contrário. }\end{array}$ \\
NOMC_NOCM NOMC & \\
\hline
\end{tabular}

observações anuais (52 países importadores $\times 51$ fluxos de importação bilateral) e 53.040 observações para todo período (2.652 observações $\times 20$ anos). A variável dependente, importações bilaterais em dólares americanos correntes, foi obtida a partir do UN COMTRADE. Já o PIB dos países, também medido em dólares americanos correntes, e a população foram obtidos do Banco Mundial. As dummies referentes aos APCs e a OMC foram construídas pelos autores. Os países foram separados entre dois grupos, os desenvolvidos e os desenvolvimentos. Os critérios utilizados foram com base nos dados do Banco Mundial. ${ }^{14}$

\section{RESULTADOS EMPÍRICOS}

Antes de apresentar os resultados encontrados, cabe ressaltar que o modelo foi submetido a alguns testes. 0 primeiro teste econométrico realizado buscava descobrir se era necessário controlar a heterogeneidade bilateral do exportador e do importador. Assim, o teste utilizado foi baseado na proposta de Greene (2008), que testa se há diferença entre os pares. Esse teste apresenta a hipótese nula $\left(H_{0}\right)$ de

Egito, Islândia, Noruega, Suíça, Áustria, Finlândia, Suécia, Marrocos, Tunísia, Alemanha, Bélgica, Chipre, Dinamarca, Espanha, França, Grécia, Holanda, Hungria, Inglaterra, Irlanda, Itália, Polônia, Portugal, Romênia, Chile, China, Coréia do Sul, Hong Kong, Índia, Israel, Japão e Turquia.

${ }^{14}$ Os países desenvolvidos foram considerados países de alta renda membros da OCDE. Os países em desenvolvimento o restante. Para mais detalhes, ver http://www.worldbank.org. 
que o efeito fixo dos pares de países $\left(\alpha_{j i}\right)$ é o mesmo para todos os pares. Dessa forma, não rejeitando a hipótese nula, a estrutura de dados agrupados seria a indicada. Por outro lado, quando ocorre a rejeição da hipótese nula, o teste indica a necessidade de controlar a heterogeneidade, ou seja, exige-se a utilização de dados em painel. Conforme observado na Tabela 5, o teste rejeitou fortemente a hipótese nula. Além desse, foi testada a necessidade de se incluir dummies de tempo para controlar o ciclo de negócios e quaisquer outros choques não percebidos. Novamente, o teste rejeitou a hipótese nula de que as dummies temporais são iguais a zero e, desta forma, elas também devem ser inseridas no modelo.

No que diz respeito aos resultados, eles se encontram na Tabela 6. Cabe salientar ainda que os erros são robustos para levar em conta a presença de heterocedasticidade e autocorrelação serial dos resíduos. Percebe-se que o PIB do importador e do exportador foram significativos a $99 \%$ e apresentaram o sinal de acordo com o esperado, porém o PIB do importador teve maior importância do que o do exportador. Já a população foi significativa a 99\% apenas para o importador, apresentando um sinal negativo.

O coeficiente associado aos pares de países que ambos são membros da OMC, porém o importador $j$ é membro de um APC no qual o exportador $i$ não é membro, não foi significativo ( $a p c_{-} o m c$ ). Assim, não é possível afirmar que a criação da OMC incrementou o comércio fora do bloco. Se analisar essa dummy em conjunto com as dummies dos APCs, que foram significativas e positivas (Mercosul, Nafta, União Europeia, Asean e EFTA), o resultado sugere que a abertura regional foi discriminatória, uma vez que ela não foi estendida à abertura multilateral. Mais discriminatório ainda foi o comportamento associado aos importadores $j$, membros da OMC e de um APC no qual o exportador $i$ não é membro do acordo e nem membro da OMC ( $\left.a p c_{-} n o m c\right)$, uma vez que a variável apresentou um sinal negativo e significativo a 99\%. Isso significa que a não participação na OMC teve um efeito negativo nesse tipo de comércio. Observa-se então que existiu discriminação também no processo de abertura multilateral já que os países membros não foram obrigados a estenderem os mesmos privilégios da OMC aos não membros, o que, de certa forma, era de se esperar dado o principal que orienta a instituição, o princípio da MFN. Esses resultados divergem do estimado por Subramanian \& Wei (2007), que encontraram impactos positivos e significativos em ambos coeficientes, devido ao fato de que alguns países terem realizado liberação tarifária unilateral, e o de Rose (2004), o qual não encontrou benefícios na adesão dos países à OMC.

Contudo, da mesma maneira que Subramanian \& Wei (2007), observa-se que os resultados obtidos sugerem que a OMC promoveu o comércio de forma diferente entre países desenvolvidos e em desenvolvimento. Conforme já salientando, a separação desses grupos é necessária, dadas as assimetrias existentes na OMC, que anteriormente foram apresentadas. No entanto, enquanto os autores encontraram que a OMC teve maior êxito em alavancar o comércio entre países desenvolvidos e membros da instituição, entre 1950 e 2000, o resultado estimado aqui diverge dos encontrados por Subramanian \& Wei (2007), dado que a dummy omcd_omcd não foi significativa. Assim, para o período analisado, de 1990 a 2009, a OMC não teria aumentado o comércio entre os membros desenvolvidos. Esse resultado pode estar ligado ao período analisado nesse artigo, pois é provável que os países desenvolvidos tiveram maiores beneficios com liberalização comercial e, até mesmo, um incremento no comércio bilateral, num período anterior ao analisado, ainda sob a regência do GATT. Faz sentido pensar nisto, pois os países desenvolvidos foram os membros pioneiros do GATT e foram eles que lideraram, durante muitos anos, as negociações multilaterais, liberalizando setores nos quais eles tinham maior interesse. Por sinal, os países desenvolvidos

Tabela 5. Testes de Especificação do Modelo para Painel.

\begin{tabular}{lc}
\hline Testes & $p$-valor \\
\hline Teste de diferença entre os pares: $F(2.651,50.355)$ & 0,000 \\
Teste das dummies de tempo: $F(19,2.651)$ & 0,000 \\
\hline
\end{tabular}


Tabela 6. Resultados do modelo.

\begin{tabular}{|c|c|c|c|c|c|}
\hline Variáveis & Coeficiente & $\sigma$ & Variáveis & Coeficiente & $\sigma$ \\
\hline$l p i b_{-} j$ & 0,8077 & $0,0530^{*}$ & $a p c_{-} n o m c$ & $-0,3301$ & $0,0802^{*}$ \\
\hline$l p i b_{-} i$ & 0,6566 & $0,0600^{*}$ & omcd_omcd & 0,0332 & 0,0443 \\
\hline$l p o p_{-} j$ & $-1,1486$ & $0,2273^{*}$ & omcd_omcs & 0,2867 & $0,0639 *$ \\
\hline$l p o p_{-} i$ & $-0,2355$ & 0,3007 & omcd_nomc & 0,0770 & 0,0770 \\
\hline Merc & 0,9540 & $0,2514^{*}$ & $o m c s_{-} o m c$ & 0,2772 & $0,0715^{*}$ \\
\hline$m e r c_{-} i m p$ & 0,5683 & $0,0829^{*}$ & omcs_nomc & 0,0859 & 0,0837 \\
\hline merc_exp & $-0,1470$ & $0,0701^{* *}$ & nomc_no cm & $-0,2645$ & 0,1391 \\
\hline nafta & 0,3261 & $0,0814^{*}$ & $d a 1991$ & $-0,0375$ & $0,0082 *$ \\
\hline nafta_imp & 0,1248 & 0,0706 & da1992 & $-0,0641$ & $0,0161^{*}$ \\
\hline nafta_exp & $-0,1484$ & $0,0401^{*}$ & $d a 1993$ & $-0,0731$ & $0,0231^{*}$ \\
\hline can & 0,2648 & 0,3510 & da1994 & $-0,0786$ & $0,0233^{*}$ \\
\hline$c a n \_i m p$ & 0,0129 & 0,1365 & $d a 1995$ & $-0,1210$ & $0,0275^{*}$ \\
\hline can_exp & $-0,0701$ & 0,0735 & $d a 1996$ & $-0,1145$ & $0,0292^{*}$ \\
\hline asean & 0,3087 & $0,1433^{* *}$ & $d a 1997$ & $-0,0495$ & 0,0291 \\
\hline asean_imp & $-0,0937$ & 0,0562 & $d a 1998$ & $-0,0236$ & 0,0307 \\
\hline asean_exp & 0,0157 & 0,0794 & da1999 & $-0,0222$ & 0,0330 \\
\hline$e c$ & 0,3298 & $0,0733^{*}$ & da2000 & 0,0670 & $0,0328^{* *}$ \\
\hline$e c_{-} i m p$ & 0,0595 & 0,0610 & $d a 2001$ & 0,0402 & 0,0330 \\
\hline$e c_{-} \exp$ & 0,1797 & $0,0650^{*}$ & da2002 & $-0,0370$ & 0,0354 \\
\hline efta & 0,2318 & $0,0881^{*}$ & da2003 & $-0,0825$ & $0,0395^{* *}$ \\
\hline efta_imp & 0,0359 & 0,0664 & da2004 & $-0,0759$ & 0,0445 \\
\hline efta_exp & 0,1581 & $0,0651^{* *}$ & $d a 2005$ & $-0,0714$ & 0,0474 \\
\hline pafta & 0,5138 & 0,2969 & da2006 & $-0,0614$ & 0,0502 \\
\hline pafta_imp & $-0,0179$ & 0,0575 & da2007 & $-0,1105$ & 0,0568 \\
\hline pafta_exp & $-0,0717$ & 0,0887 & da2008 & $-0,1199$ & 0,0620 \\
\hline$a p c_{-} o m c$ & $-0,0388$ & 0,0445 & da2009 & $-0,2679$ & $0,0610^{*}$ \\
\hline \multicolumn{4}{|c|}{$\mathrm{N}^{\mathrm{o}}$ de observações } & \multirow{2}{*}{\multicolumn{2}{|c|}{$\begin{array}{r}53 \\
20.485,30[0,000]\end{array}$}} \\
\hline \multicolumn{4}{|l|}{ Wald $\chi^{2}(52)$} & & \\
\hline \multicolumn{4}{|c|}{ Teste de Hausman $\chi^{2}(33)$} & \multicolumn{2}{|c|}{$1.305,04[0,000]$} \\
\hline \multicolumn{4}{|c|}{ Teste de Hausman Robusto $F(33,2.651)$} & \multicolumn{2}{|c|}{$5,02[0,000]$} \\
\hline
\end{tabular}

Nota: Erros robustos clusterizado no par.

${ }^{*}$ e ${ }^{* *}$ denotam, respectivamente, nível de confiança de $99 \%$ e $95 \%$. 
tiveram um cronograma de liberalização mais rigoroso do que os demais. ${ }^{15}$

Por outro lado, o coeficiente estimado para os países membros da OMC, considerando países importadores como desenvolvidos e exportadores em desenvolvimento, foi positivo e estatisticamente significante a $99 \%$ (omcd_omcs). Esse resultado também foi encontrado por Subramanian \& Wei (2007). Porém aqui, esse tipo de comércio norte-sul foi o que a OMC deve maior êxito em alavancar, com crescimento médio de $33 \%\left(e^{0,2867}=1,33\right)$ para o período analisado. Se levar em conta novamente o período analisado, esse resultado também faz sentido, uma vez que os países em desenvolvimento entraram, de fato, nas negociações da OMC posteriormente aos desenvolvidos e os setores de seu interesse só passaram a ser liberalizados na rodada Uruguai. E, durante a rodada Uruguai, houve uma redução do grau de protecionismo dos países desenvolvidos em relação à produtos agrícolas e têxteis, exportados justamente pelos países em desenvolvimento. De modo complementar, o coeficiente da dummy associado a países importadores desenvolvidos que são membros da OMC com países exportadores não pertencentes à organização, foi considerado estatisticamente não diferente de zero (omcd_nomc). Assim, os resultados indicam mais uma vez houve discriminação no processo de abertura multilateral.

Os coeficientes estimados das dummies dos países em desenvolvimento pertencentes à OMC, de maneira semelhante ao dos países desenvolvidos, indicam que houve discriminação entre membros e não membros. O coeficiente de importação entre membros foi positivo e significativo a $99 \%$ (omcs_omc). Nesse caso, o crescimento médio para o período foi de $32 \%$. Isso pode ser explicado pela significativa liberalização comercial promovida pelos países em desenvolvimento durante a rodada Uruguai, com as tarifas de importação, em alguns casos, declinando em mais de $50 \%$. Já o coeficiente associado à importação de países em desenvolvimento membros da OMC cujo exportador não é membro da organização não foi significativo (omcs_nomc). Por fim, era de se esperar que o comércio entre não membros da instituição não aumentasse e, de fato, isto é o que foi observado nesse artigo, dado que a dummy não foi significativa (nomc_nomc). Esse resultado também foi encontrado por Subramanian \& Wei (2007).

De acordo com os resultados obtidos, é possível verificar que as assimetrias testadas no trabalho de Subramanian \& Wei (2007) não se sustentaram ao longo do tempo, tendo se invertido no período mais recente, entre 1990 e 2009. Os autores sugeriam que os países desenvolvidos, entre 1950 e 2000, por estarem mais engajados com a ideia do livre comércio e estarem relativamente mais integrados, tiveram um aumento no comércio bilateral maior do que com os membros em desenvolvimento, pois esses não teriam apresentado o mesmo comprometimento com a liberalização. 0 que se observou, no período 1990-2009, foi um aumento do comércio entre os países em desenvolvimento membros da OMC, dada a sua recente liberalização multilateral e a elevação das importações dos países desenvolvidos dos países em desenvolvimento, fruto da liberalização de produtos sensíveis da pauta exportadora dos países em desenvolvimento.

\section{CONCLUSÕES}

Os resultados estimados neste artigo também sustentam a ideia de que existe discriminação entre membros e não membros, e que a OMC foi capaz de gerar um incremento significativo no comércio mundial. Contudo, os coeficientes de importação dos membros desenvolvidos e em desenvolvimento sugerem que, durante 1990 a 2009, a OMC foi mais benéfica para o comércio dos países em desenvolvimento. Esse fato pode ter ocorrido devido a maior abertura comercial entre os países desenvolvidos antes da rodada Uruguai, ou seja, o seu grau de protecionismo nos anos 1990 já era pequeno. No período mais recente, especialmente após a rodada Uruguai, a abertura comercial multilateral mais importante ocorreu justamente nos países em desenvolvimento, que apresentavam um maior grau de protecionismo.

Além disso, a liberalização adicional dos países desenvolvidos beneficiou alguns setores nos quais os países em desenvolvimento são grandes exportadores, como produtos agrícolas e têxteis. Isso ajuda a

\footnotetext{
${ }^{15}$ Esse resultado pode estar associado à periodicidade (anual) das estimações, a amostra dos países e a metodologia econométrica utilizada, que não coincidem com os artigos mencionados.
} 
explicar porque a as importações dos países desenvolvidos só aumentou, de forma significativa, dos países em desenvolvimento e porque houve uma elevação do comércio entre os países em desenvolvimento membros da OMC. Além disso, houve o crescimento no número de países participantes, em sua maioria composta de países em desenvolvimento, que receberam um cronograma de liberalização comercial mais rigoroso que os membros antigos.

Portanto, os resultados sugerem que os países em desenvolvimento, no período 1990-2009, foram os que mais se beneficiaram do aumento do comércio mundial promovido pela OMC, ao contrário do que havia ocorrido entre 1950 e 2000. O artigo mostrou que a OMC teve êxito em atingir seu objetivo de ampliar os fluxos comerciais, embora a abertura comercial novamente tenha ocorrido de forma assimétrica entre países desenvolvidos e em desenvolvimento. A diferença é que, nesse período mais recente, devido a maior liberalização comercial dos países em desenvolvimento da OMC, foi nesses países que ocorreu a maior promoção do comércio provocada pela abertura multilateral, ao contrário do que haviam estimado Subramanian \& Wei (2007), para um período anterior.

\section{REFERÊNCIAS BIBLIOGRÁFICAS}

Aitken, N. D. (1973). The effect of the EEC and EFTA on European trade: A temporal cross-section analysis. American Economic Review, 63(5), 881-92.

Anderson, J. E. (1979). A theoretical foundation for the gravity equation. American Economic Review, 69, 106-116.

Anderson, J.E., \& van Wincoop, E. (2003). Gravity with gravitas: A solution to the Border Puzzle. American Economic Review, 93(1), 170-192. doi: 10.1257/000282803321455214

Baldwin, R., \& Taglioni, D. (2006, September). Gravity for dummies and dummies for gravity equations (NBER Working Paper $\mathrm{N}^{0}$ 12516). National Bureau of Economic Research. doi: 10.3386/w12516

Bergstrand, J. (1985). The gravity equation in international trade: Some microeconomic foundations and empirical evidence. The Review of Economics and Statistics, 67(3), 474-81.

Bhagwati, J., Krishna, P. \& Panagariya, A. (Eds.). (1999). Trading blocs: Alternative approaches to analyzing preferential trade agreements. Cambridge, MA: MIT Press.

Carrere, C. (2006). Revisiting the effects of regional trade agreements on trade flows with proper specification of the gravity model. European Economic Review, 50(2), 223-247.

Cheng, I.-H., \& Wall, H.J. (2004, July). Controlling for heterogeneity in gravity models of trade and integration (Working Paper $\mathrm{N}^{0}$ 1999-010E). Federal Reserve Bank of St. Louis. Disponível em: http://research.stlouisfed .org/wp/1999/1999-010.pdf

Deardorff, A. (1998). Determinants of bilateral trade: Does gravity work in a neo-classical world? In J. A. Frankel (Ed.), Regionalization of the world economy (pp. 7-31). Chicago: University of Chicago Press.

Egger, P. (2005). Alternative techniques for estimation of cross-section gravity models. Review of International Economics, 13(5), 881-891. doi: 10.1111/j.1467-9396.2005.00542.x

GATT-General Agreement on Tariffs and Trade (1994). The results of the Uruguay Round of multilateral trade negotiations / Market access for goods and services: Overview of the results. Geneva: GATT Secretariat.

Greene, W. H. (2008). Econometric analysis (6⿳亠 ed.). New Jersey: Pearson Prentice Hall.

Helpman, E. (1987). Imperfect competition and international trade: Evidence from fourteen industrial countries. Journal of the Japanese and International Economies, 1(1), 62-81.

Helpman, E., \& Krugman, P. (1995). Market structure and foreign. Cambridge, MA: MIT Press.

Helpman, E., Melitz, M. \& Rubinstein, Y. (2008). Estimating trade flows: Trading partners and trading volumes. The Quarterly Journal of Economics, 123(2), 441-487. doi: 10.1162/qjec.2008.123.2.441

Krugman, P. (1991). The move toward free trade zones. Economic Review, Federal Reserve Bank of Kansas City, 76, 5-25.

Linnemann, H. (1966). An econometric study of international trade flow. Amsterdam: North-Holland.

Magee, C. S. P. (2008). New measures of trade creation and trade diversion. Journal of International Economics, 75(2), 349-362. 
Matyas, L. (1997). Proper econometric specification of the gravity model. World Economy, 20(3), 363-368. doi: 10.1111/1467-9701.00074

OMC-World Trade Organization (2013). RTA database. URL: http://rtais.wto.org/UI/PublicMaintainRTAHome.aspx. Acessado em 25 de Fevereiro de 2013.

Poyhonen, P. (1963). A tentative model for the volume of trade between countries. Weltwirtschatftliches Archiv, 90, 93-99.

Recalde, M., Florensa, L. M. \& Iturralde, I. (2008). Gravity equation and trade agreements: A different econometric approach. Revista de Economía y Estadística, XLVI(2), 83-104.

Reis, M. d. (2012). Os efeitos do novo regionalismo sobre o comércio (Dissertação de mestrado). PPGE, Universidade do Vale do Rio dos Sinos-UNISINOS, São Leopoldo, RS.

Rose, A. K. (2004). Do WTO members have more liberal trade policy? Journal of International Economics, 63(2), 209-235.

Santos Silva, J., \& Tenreyro, S. (2006). The log of gravity. The Review of Economics and Statistics, 88(4), 641-658.

Siliverstovs, B., \& Schumacher, D. (2007). Estimating gravity equations: To log or not to log? (Discussion Paper of DIW Berlin $\mathrm{N}^{0} 739$ ). DIW Berlin, German Institute for Economic Research.

Soloaga, I., \& Winters, A. L. (2001). Regionalism in the nineties: What effect on trade? The North American Journal of Economics and Financ, 12(1), 1-29

Subramanian, A., \& Wei, S.-J. (2007). The WTO promotes trade, strongly but unevenly. Journal of International Economics, 72(1), 151-175.

Summers, L. (1991). Regionalism and the world trade system. Economic Review, Federal Reserve Bank of Kansas City, 76, 295-302.

The Economist. (2012, Sep 8). Goodbye Doha, hello Bali. The Economist. Acessado em 9 de outubro de 2012: http://www.economist.com/node/21562196

Thorstensen, V. (2001). OMC-Organização Mundial do Comércio: As regras do comércio internacional e a nova rodada de negociações multilaterais (2 ${ }^{\underline{a}}$ ed.). São Paulo: Edições Aduaneiras.

Tinbergen, J. (1962). Shaping the world economy: Suggestions for an international economy policy. New York: Twentieth Century Fund.

Wei, S.-J. (1996, Apr). Intra-national versus international trade: How stubborn are nations in global integration? (NBER Working Paper $\mathrm{N}^{0}$ 5531). National Bureau of Economic Research. doi: 10.3386/w5531

Westerlund, J., \& Wilhelmsson, F. (2009). Estimating the gravity model without gravity using panel data. Applied Economics, 43(6), 641-649. doi: 10.1080/00036840802599784

Wonnacott, P., \& Lutz, M. (1989). Is there a case for more free trade areas? In J. Schott (Ed.), Free trade areas and U.S. trade policy (pp. 59-89). Washington: Institute for International Economics.

Wooldridge, J. M. (2010). Introdução à econometria: Uma abordagem moderna [Tradução da quarta edição norte americana]. São Paulo: Cengage Learning. 